\title{
ASSESSMENT OF THE HOMOPHOBIC ATTITUDES OF THE EMERGENCY DEPARTMENT PROFESSIONALS: DESCRIPTIVE SURVEY STUDY
}

\author{
Mehmet Murat Oktay ${ }^{1}$, Mustafa Boğan ${ }^{2}$, Mustafa Sabak ${ }^{3}$, Hasan Sultanoğlu ${ }^{2}$, Hüseyin Narcı ${ }^{4}$ \\ ${ }^{1}$ Vocational High School, Hasan Kalyoncu University, Gaziantep, Turkey \\ ${ }^{2}$ Emergency Department of Düzce University, Düzce, Turkey \\ ${ }^{3}$ Emergency Department of Nizip State Hospital, Gaziantep, Turkey \\ ${ }^{4}$ Emergency Department of Mersin University, Mersin, Turkey
}

\begin{abstract}
INTRODUCTION: Homophobia can be defined as fear, hatred, discrimination, and even violent feelings and behaviors developed towards individuals with sexual orientations different to other individuals of the same sex. Our study was conducted to assess the levels of homophobia among emergency medicine specialists, practitioners, nurses, and other health care professionals working in the emergency department (ED).

MATERIAL AND METHODS: This study was carried out as a descriptive survey study in Gaziantep, Turkey, between July 7, 2018 and August 30, 2018. The data was collected using a Google survey form link sent to volunteers via mobile phone.

RESULTS: The mean age of the patients was $30.85 \pm 7(20-53)$ years. While $77.5 \%(n=117)$ of the volunteers who participated in the study worked in state hospitals, $11.3 \%(n=17)$ worked in a private hospital. The Cronbach's Alpha value was calculated as 92.3 and the scale average score as $85.42 \pm 12.33$ as a result of the evaluation of the Likert-type scale. While 69 (45.7\%) people were lower in homophobia, 82 (54.3\%) were higher in homophobia. A difference in attitudes towards homosexuals was only observed between those who had a homosexual friend or acquaintance and those who did not $(p=0.009)$. Accordingly, those with homosexual friends were determined to be less homophobic. On the other hand, it was observed that those with a homosexual acquaintance and those with no homosexual acquaintances were more homophobic.

CONCLUSION: In our study, it was shown that emergency medicine specialists and other health professionals working in the ED exhibit high levels of homophobic attitudes and behaviors. Including lesbian, gay, bisexual, transgender, intersex (LGBT-I) health problems in in-service trainings may contribute to the improvement of homophobic attitudes.
\end{abstract}

KEY WORDS: attitude of health personnel, homophobia, emergency service, hospital

Disaster Emerg Med J 2021; 6(3): 119-124

\section{INTRODUCTION}

Homophobia can be defined as fear, hatred, discrimination, and even violent feelings and behaviors developed towards individuals with sexual orientations different to other individuals of the same sex [1]. In recent years, lesbian, gay, bisexual, transgender, intersex (LGBT-I) individuals have become more visible in social life, has also made homophobic attitudes towards sexual minorities more common. Health care providers should provide equal care to all social 
groups, but very little is known about their attitudes towards sexual minorities [2]. On the other hand, it is also known that LGBT-I individuals face certain challenges when accessing health services due to the homophobic attitudes of health professionals. There are studies reporting that these individuals delay medical care and preventive medical care due to the rejection of health care by service providers, because they encounter verbal harassment in the medical setting, and due to the discrimination and disrespect they experience during their visits to health institutions [3]. All these situations may result in the LGBT-I individuals being discouraged from benefiting from health services as much as they need due to their concerns that they will be exposed to the homophobic attitudes of health professionals if their sexual orientation is revealed.

In such cases where health care professionals cannot effectively manage their fears against what is different to themselves, they may not be able to deliver effective, equal, and quality health care services needed by the patient or by an injured person. If this situation occurs in the emergency department (ED) setting while the patient or the injured person faces a threat to life, the service provider will face legal liabilities.

Our study was conducted to assess the levels of homophobia among emergency medicine specialists, practitioners, nurses and other health care professionals working in EDs. In this regard, to the best of our knowledge, our study is the first conducted in the ED setting. The results of this study will be beneficial by providing resources to improve the attitudes towards individuals with different sexual identities and orientations in the emergency department health services.

\section{MATERIAL AND METHODS}

Our study was a descriptive study assessing the levels of homophobia among emergency medicine specialists, practitioners, nurses and other health professionals working in EDs in the city of Gaziantep, Turkey. It was designed to draw attention to medical errors that may have been a result of homophobic attitudes. The objective of the study was to investigate the attitudes of emergency department staff towards homosexuality and to determine the need for training programs for health professionals working in the ED. The study was completed in eight months with the approval of the ethical committee obtained from the Hasan Kalyoncu University (date 05/03/2019, number: 2019-26).

The universe of the study comprised of emergency department staff of two university hospitals, one training and research hospital, three public hospitals, and two private hospitals in the city of Gaziantep. In the hospitals listed above, there is a total of 398 ED staff of which six are emergency medicine lecturers, 54 are emergency medicine specialists and residents, 113 are practitioners, 165 are emergency department nurses, 30 are paramedics, and 30 are emergency medicine technicians (EMT). Among these, 151 participants volunteered to participate in our study (37.9\%), of which four were emergency medicine lecturers, 36 were emergency medicine specialists and residents, 45 were practitioners, 50 were emergency department nurses, 11 were EMTs, and 5 were paramedics. During the study, the study was announced to 398 health professionals working in the seven hospitals in our city by sending a message to their mobile phones. The Google survey information form and written questionnaire converted into a research form sharable over the internet were sent to the 151 volunteers as a link (https://forms.gle/HghWHiWMSbRNev1S8). Considering the intensive ED environment, the participants were specifically asked to fill in the forms in the non-working hours.

The questionnaire consisted of two parts. The first part included eight questions assessing the demographic features. In the second part, the Hudson and Rickett Homophobia Scale was used for attitudes towards homosexuals. The scale developed in 1980 was adapted into Turkish by Sakallı and Uğurlu (2001). The version of the scale adapted into Turkish consists of 24 items. In this adaptation, the item "it would not bother me to walk through a predominantly gay section of town" has been removed from the scale, because no such area existed in the city where the scale was applied (Ankara) [4]. Among the total of 35 studies conducted in our country until 2017, the Turkish adaptation of the attitude scale developed by Hudson and Ricketts was used in 10 [5]. In this regard, its psychometric properties have been tested in many studies. While the original English version had demonstrated a Cronbach Alpha $=90$, the Turkish adaptation was found to have high reliability with a Cronbach Alpha $=94$ [6]. In the scale, the participants were asked to evaluate the items on a 6-point Likert-type scale. Each question in the questionnaire was scored between 1 (strongly 
disagree) and 6 (strongly agree). High scores were associated with an increase in homophobic attitudes. The total score was calculated by reversing the items $5,6,8,10,11,13,17,18,23$, and 24 of the scale, and the median value of the total score was calculated, and based on this median score, the participants were divided into two groups according to the low and high levels of homophobia.

Our study was a descriptive study. There were no hypotheses. While evaluating the study results, no hypothesis was tested; variables in the data set were summarized using descriptive values, such as frequency distributions, mean, standard deviation, minimum and maximum values of the results.

The consistency of the data with normal distribution was tested using the Shapiro-Wilk test, the comparison of the normally distributed characteristics in 2 independent groups was made using the Student's t-test, and the Mann-Whitney $U$ test was used to compare the non-normally distributed characteristics in 2 independent groups. In addition, to compare the numerical data in more than 2 independent groups, the one-way variance analysis (ANOVA) and the LSD multiple comparison tests were used, and for the non-normally distributed characteristics, the Kruskal-Wallis and the all pairwise multiple comparison test were used. The Cronbach alpha coefficients were calculated to test the validity and reliability. The associations for two quantitative measurements were calculated by the Pearson correlation coefficient. The mean \pm standard deviation values were given for numerical variables, and number and \% values were given for categorical variables as the descriptive statistics. The SPSS Windows version 24.0 software bundle was used for the statistical analyses and a $p$ value of $<0.05$ was considered statistically significant.

\section{RESULTS}

In our study, the Cronbach alpha value was calculated as 92.3 and the scale average score as $85.42 \pm 12.33$ as a result of the evaluation of the Likert-type scale. The lowest score of the participants was calculated as 43 and the highest as 143 . Based on this, while 5 individuals (3.3\%) with scores equal to the median value and 64 individuals (42.4\%) that fell under the median value were regarded as less homophobic, 82 individuals (54.3\%) that fell above this value were regarded as more homophobic. A total of 151 people with an average age of
$30.85 \pm 7$ (20-53) years participated in our study. Of the participants, $49.7 \%(n=75)$ were male and $50.3 \%(n=76)$ were female, $51.7 \%(n=78)$ were married, $48.3 \%(n=73)$ were single. Among the health care workers that participated in the study, $45.7 \%(n=69)$ were university graduates, $23.8 \%$ ( $n=36)$ had either completed or were continuing their residency education, and $12.6 \%(n=16)$ had completed a doctorate or postgraduate degree. Nurses comprised $33.18 \%(n=50)$, practitioners $29.8 \%(n=45)$, and emergency medicine lecturers comprised $2.6 \%(n=4)$ of our participants. While $77.5 \%(n=117)$ of the volunteers who participated in the study worked in state hospitals, $11.3 \%$ $(n=17)$ worked in a private hospital. While only $14.6 \%(n=22)$ of the participating health professionals had a homosexual friend, $66.9 \%(n=101)$ had no homosexual friends or acquaintances (Tab. 1).

It was identified that the homophobia levels of men and women who participated in the study were similar according to the scale analysis results and that the difference in gender did not result in a different attitude towards homosexuals. A similar situation was also observed in professional commitment and staff of different hospitals. It was also observed that the educational status of the participants did not result in different attitudes towards homosexuals. In our study, a difference in attitudes towards homosexuals was only observed between those who had a homosexual friend or acquaintance and those who did not $(p=0.009)$. Accordingly, those with homosexual friends were determined to be less homophobic. On the other hand, it was observed that those with a homosexual acquaintance and those with no homosexual acquaintances were more homophobic (Tab. 1).

\section{DISCUSSION}

When the results of our study are compared to the studies that used the same scale, it is seen that our participants exhibited higher levels of homophobia. This could be explained by the fact that our region has a more conservative structure than metropolitan cities. It is possible to say that homophobic attitudes and behaviors are common in Turkey, which has a conservative social structure. Studies reveal that Western Europe and Latin America countries are societies with low levels of homophobia, while Africa and Middle Eastern countries are societies with high levels of homophobia [6, 7]. The 


\begin{tabular}{|c|c|c|c|c|}
\hline & & Number & Average & Median \\
\hline \multirow{2}{*}{$\begin{array}{l}\text { Gender } \\
p=0.332\end{array}$} & Male & 75 & $84.4 \pm 11$ & 86 \\
\hline & Female & 76 & $86.4 \pm 13.5$ & 88 \\
\hline \multirow{2}{*}{$\begin{array}{l}\text { Marital Status } \\
p=0.493\end{array}$} & Single & 78 & $84.7 \pm 13.2$ & 86 \\
\hline & Married & 73 & $86.1 \pm 11.3$ & 87 \\
\hline \multirow{5}{*}{$\begin{array}{l}\text { Last education program graduated } \\
\text { from } \\
p=0.179\end{array}$} & High school & 15 & $90.5 \pm 7.9$ & 91 \\
\hline & Two-year college & 12 & $89.7 \pm 19.9$ & 85 \\
\hline & University & 69 & $83.7 \pm 10.8$ & 85 \\
\hline & Postgraduate degree/Doctorate & 19 & $85 \pm 18.4$ & 86 \\
\hline & Specialty in Medicine & 36 & $85.2 \pm 8.7$ & 87 \\
\hline \multirow{6}{*}{$\begin{array}{l}\text { Profession } \\
p=0.432\end{array}$} & Emergency Medicine Technician & 11 & $94.9 \pm 18.20$ & 90 \\
\hline & Paramedic & 5 & $82.4 \pm 9$ & 84 \\
\hline & Nurse & 50 & $85.2 \pm 9.7$ & 86 \\
\hline & Practitioner & 45 & $83.2 \pm 12.5$ & 85 \\
\hline & Emergency Medicine Specialist & 36 & $85.2 \pm 8.8$ & 87.5 \\
\hline & Emergency Medicine Lecturer & 4 & $91.5 \pm 34$ & 89,5 \\
\hline \multirow{3}{*}{$\begin{array}{l}\text { Hospital of employment } \\
p=0.625\end{array}$} & State Hospital & 117 & $85.6 \pm 12.7$ & 87 \\
\hline & Private Hospital & 17 & $82.8 \pm 9$ & 82 \\
\hline & University Hospital & 17 & $86.6 \pm 12.6$ & 89 \\
\hline \multirow[t]{3}{*}{ Acquaintance with homosexuals } & $\mathrm{No}^{\mathrm{b}}$ & 101 & $86 \pm 11.8$ & 87 \\
\hline & I have an acquaintance ${ }^{b}$ & 28 & $88.6 \pm 12$ & 87.5 \\
\hline & I have a friend ${ }^{a}$ & 22 & $78.4 \pm 12.7$ & 80 \\
\hline
\end{tabular}

* Paired comparisons after the ANOVA test were obtained with the LSD test. Each different index of a, b, c shows a statistically significant difference. $P<0.05$ was considered statistically significant

most important result of our study was that $54.3 \%$ ( $n=82$ ) of emergency medicine specialists and other ED service providers exhibited high levels of homophobic attitudes. In similar studies conducted in our country outside the ED, this rate has been calculated as $47.3 \%$ and $49.2 \%[6,8]$. In a study conducted in the United States of America, half of the participants had high levels of non-homophobic attitudes [9].

It was shown in other studies using different scales that $30 \%$ of health services students in Australia were uncomfortable with treating lesbians and $27 \%$ were uncomfortable with treating gay men [10], and in Sweden, it was shown that both professional care staff and nursing students had homophobic attitudes [11]. In a study conducted in Colombia, it was identified that the frequency of homophobia among nursing students was between $7 \%$ and $16 \%$ [12]. Similar studies conducted in other countries also revealed that doctors and other health professionals commonly exhibited homophobic attitudes $[2,3,13,14]$.
Unlike other studies, our study was conducted in EDs and it is the first study of its kind in this regard. Due to the fact that emergency medicine specialists and other ED service providers make instant vital decisions in life-threatening emergency conditions unlike other health disciplines, homophobic attitude of the ED staff poses a higher risk for LGBT-I individuals. In such cases, they must be free of any kind of emotional stress or prejudice. Otherwise, the patients or an injured person being seriously harmed or losing their life becomes a matter at hand.

Contrary to many conducted studies, it was observed in our study that there was no association between the levels of homophobia and parameters such as gender and professional commitment, whereas studies conducted in our country and other countries have shown that women have lower levels of homophobic attitudes than men $[2,4,6,15-20]$.

Similarly, there are studies showing that there is a significant association between the educational levels and homophobic attitudes, and that the homophobic attitudes of participants decrease as 
their educational levels increase. In these studies, it has been revealed that parameters such as having completed high education, and increased duration of education set the group at a lower risk for homophobic attitudes [7, 19-21]. In contradiction to these studies, in our study it was observed that variables such as the educational level, professional or academical promotions are not the parameters that reduce the homophobic attitudes among ED professionals. We think this could be related to the misconception of ED staff that sexually transmitted diseases such as HIV and HCV are more frequent among LGBT-I individuals, as much as it is related to the conservative structure of the region we live in. Studies claiming that homophobia and HIV phobia are two seperate, but strongly related attitudes are the basis of our opinion [22-24].

In our study, different attitudes towards homosexuals have been observed only between those with and without a homosexual friend $(p=0.009)$. Accordingly, it was determined that those with a homosexual friend were less homophobic. Studies conducted by Sakallı and Uğurlu [4], and Çırakoğlu [16] in our country have also yielded similar results. There are also studies showing that not having a non-heterosexual friendship or relative is also associated with homophobia [25-27]. On the other hand, it has been observed that individuals that have a homosexual acquaintance but not a friend, are more homophobic. This is consistent with studies showing that conservative individuals are likely to be more homophobic when they come into personal contact with homosexuals [28]. Based on all these studies, it could be said that establishing social relationships with LGBT-I individuals could have positive effects on homophobic attitudes.

\section{Limitations of our study}

The number of participants could not be increased any further, since the region where our study was conducted is a region inhabited mostly by conservative people. For the same reason, the results of our region will be limited in reflecting all homophobic trends across our country. Again, the fact that LGBT-I individuals are relatively less visible in our region has resulted in limited interest on this issue.

\section{CONCLUSION}

In our study, it was shown that emergency medicine specialists and other health professionals working in the ED exhibit high levels of homophobic attitudes and behaviors. The prejudices and attitudes of health professionals, particularly that of emergency medicine specialists working in the ED towards individuals with different sexual orientations may affect the quality of their communication with patients and contribute to the health inequalities among sexual minorities. If this occurs in the EDs, it will endanger the lives of the patients and injured, and also expose health care providers to legal liabilities.

Including LGBT-I health problems in the curriculum of medical education and including these subjects in in-service trainings may contribute to the improvement of homophobic attitudes.

\section{REFERENCES}

1. Herek GM. Beyond "homophobia": a social psychological perspective on attitudes toward lesbians and gay men. J Homosex. 1984; 10(1-2): 1-21, doi: 10.1300/J082v10n01_01, indexed in Pubmed: 6084028.

2. Fisher $A D$, Castellini $G$, Ristori J, et al. Who has the worst attitudes toward sexual minorities? Comparison of transphobia and homophobia levels in gender dysphoric individuals, the general population and health care providers. J Endocrinol Invest. 2017; 40(3): 263-273, doi: 10.1007/s40618-016-0552-3, indexed in Pubmed: 27639401.

3. Transgender Task Force Report. PsycEXTRA Dataset. 2000, doi: 10.1037/e373942004-012.

4. Sakalli N, Uğurlu 0. Effects of social contact with homosexuals on heterosexual Turkish university students' attitudes towards homosexuality. J Homosex. 2001; 42(1): 53-62, doi: 10.1300/j082v42n01_03, indexed in Pubmed: 11991566.

5. Orta iM, Camgöz SMA. General Overview On Research On Homophobia In Turkey. DTCF Dergisi 58. 2018; 1: 409-39.

6. Artan T, Özkan A0. Assessment Of Homophobia Levels Of Staff Employed For ASDEP. Journal of Social and Humanities Sciences Research. 2018; 5: 1501-14.

7. Lamontagne E, d'Elbée M, Ross MW, et al. A socioecological measurement of homophobia for all countries and its public health impact. Eur J Public Health. 2018; 28(5): 967-972, doi: 10.1093/eurpub/cky023, indexed in Pubmed: 29514190.

8. Aslan F, Şahin NE, Emiroğlu ON. Turkish nurse educators knowledge regarding LGBT health and their level of homophobia: A descriptive-cross sectional study. Nurse Educ Today. 2019; 76: 216-221, doi: 10.1016/j.nedt.2019.02.014, indexed in Pubmed: 30836285.

9. Schlub SM, Martsolf DS. Orthodox Christian beliefs and homophobia in baccalaureate nursing students. Nurs Forum. 1999; 34(2): 15-22, doi: 10.1111/j.1744-6198.1999.tb00982.x, indexed in Pubmed: 10603853.

10. Jones MK, Pynor RA, Sullivan G, et al. A study of attitudes toward sexuality issues among health care students in australia. J Lesbian Stud. 2002; 6(3-4): 73-86, doi: 10.1300/J155v06n03_07, indexed in Pubmed: 24804589. 
11. Röndahl G, Innala S, Carlsson M. Nursing staff and nursing students' emotions towards homosexual patients and their wish to refrain from nursing, if the option existed. Scand J Caring Sci. 2004; 18(1): 19-26, doi: 10.1111/j.1471-6712.2004.00263.x, indexed in Pubmed: 15005660.

12. Campo A, Herazo E. Homophobia among nursing students. Revista da Escola de Enfermagem da USP. 2010; 44(3): 826-30.

13. Rose L. Homophobia among doctors. BMJ. 1994; 308(6928): 586-587, doi: 10.1136/bmj.308.6928.586.

14. Sabin JA, Riskind RG, Nosek BA. Health Care Providers' Implicit and Explicit Attitudes Toward Lesbian Women and Gay Men. Am J Public Health. 2015; 105(9): 1831-1841, doi: 10.2105/AJPH.2015.302631, indexed in Pubmed: 26180976.

15. Türk Psikoloji Yazıları., doi: 10.31828/tpy.

16. Cirakoğlu OC. Perception of homosexuality among Turkish university students: the roles of labels, gender, and prior contact. J Soc Psychol. 2006; 146(3): 293-305, doi: 10.3200/SOCP.146.3.293-305, indexed in Pubmed: 16783983.

17. Basow S, Johnson K. Sex Roles. 2000; 42(5/6): 391-404.

18. Kroska A. Gender Ideology and Gender Role Ideology. The Blackwell Encyclopedia of Sociology. 2007, doi: 10.1002/9781405165518.wbeosg019.

19. Yertutanol FD, Candansayar S, Seydaoğlu G. Homophobia in Health Professionals in Ankara, Turkey: Developing a Scale. Transcult Psychiatry. 2019; 56(6): 1191-1217, doi: 10.1177/1363461518808166, indexed in Pubmed: 30484756.

20. Lewis G. Black-White Differences in Attitudes toward Homosexuality and Gay Rights. Public Opinion Quarterly. 2003; 67(1): 59-78, doi: $10.1086 / 346009$.
21. Brewer PR. Public Opinion About Gay Rights and Gay Marriage. International Journal of Public Opinion Research. 2014; 26(3): 279-282, doi: 10.1093/ijpor/edu029.

22. Herek G. Sexual Prejudice. Encyclopedia of Human Relationships., doi: 10.4135/9781412958479.n487.

23. Smith DM, Mathews WmC. Physicians' attitudes toward homosexuality and HIV: survey of a California Medical Society- revisited (PATHH-II). J Homosex. 2007; 52(3-4): 1-9, doi: 10.1300/J082v52n03_01, indexed in Pubmed: 17594969.

24. Eaton LA, Driffin DD, Kegler C, et al. The role of stigma and medical mistrust in the routine health care engagement of black men who have sex with men. Am J Public Health. 2015; 105(2): e75-e82, doi: 10.2105/AJPH.2014.302322, indexed in Pubmed: 25521875.

25. Anderssen N. Does contact with lesbians and gays lead to friendlier attitudes? a two year longitudinal study. Journal of Community \& Applied Social Psychology. 2002; 12(2): 124-136, doi: 10.1002/ casp.665.

26. Dinkel S, Patzel B, McGuire MJ, et al. Measures of homophobia among nursing students and faculty: a Midwestern perspective. Int J Nurs Educ Scholarsh. 2007; 4: Article24, doi: 10.2202/1548-923X.1491, indexed in Pubmed: 18052922.

27. Homosexuality. Conscience and Parliament. 2012: 32-48, doi: 10.4324/9780203044582-4.

28. Mestvirishvili M, Zurabishvili T, lakobidze T, et al. Exploring Homophobia in Tbilisi, Georgia. J Homosex. 2017; 64(9): 1253-1282, doi: 10.1080/00918369.2016.1244445, indexed in Pubmed: 27700910. 